\title{
SEASONAL BEACH VARIABILITY ON A SEA-BREEZE DOMINATED BEACH
}

\author{
Gabriela Medellín, CONACYT-Universidad Nacional Autónoma de México, gmedellinm@ii.unam.mx \\ Alec Torres-Freyermuth, Universidad Nacional Autónoma de México, atorresf@ii.unam.mx
}

\section{INTRODUCTION}

The knowledge of seasonal beach variability is fundamental to evaluate the beach resistance and resilience to either natural or anthropogenic perturbations. Therefore, beach monitoring programs are required to understand seasonal and long-term beach changes (e.g., Harley et al., 2010). Despite their importance, beach monitoring programs are scarce in Mexico. Thus, this study aims to analyze the inter-annual and intra-annual variability in the vicinity of coastal structures on a sea breeze dominated beach by means of high-spatial and temporal resolution beach surveys.

\section{STUDY AREA}

The study area is located on a barrier island in the Yucatan peninsula. The coastal dynamics are mainly controlled by NE sea waves associated to intense sea breeze events (Medellín et al., 2015; Torres-Freyermuth et al., 2017) and NNW swell often associated to cold-front passages (Reding, 1992). The sea breeze dominated season occurs from April to September. Furthermore, the presence of coastal structures alters the natural dynamics in this region. Sisal beach morphodynamics is affected by the presence of the Port Jetty and the Pier (Figure 1) that induce spatial gradients in the alongshore sediment transport.

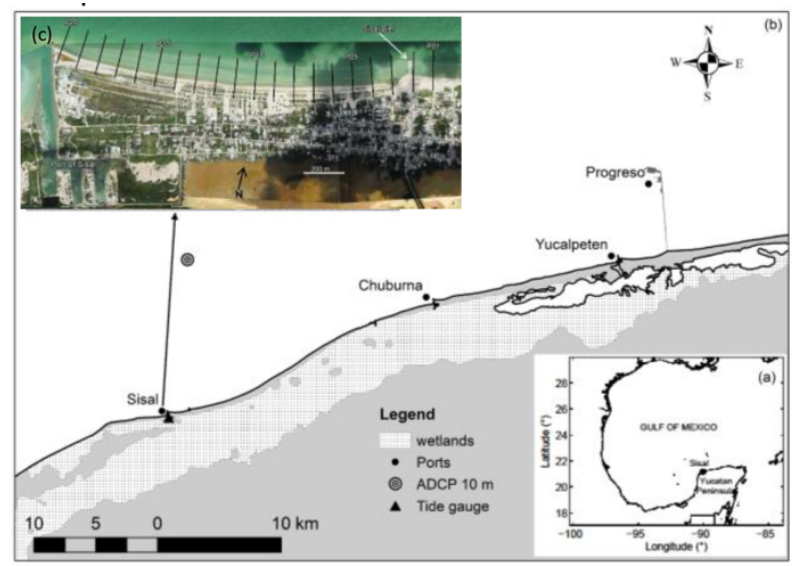

Figure 1 - Study area showing: (a) Sisal location in the Yucatán Peninsula, (b) the location of the port, ADCP, and tidal gauge, and (c) the beach transects employed for the monitoring program.

\section{METHODS}

A beach monitoring program, along a 2-km stretch of coast, has been carried out in the study area (Figure 1c). It aims to improve our understanding on the seasonal and long-term morphodynamics of Sisal beach. Thus, twenty cross-shore beach transects, separated by $100 \mathrm{~m}$ in the alongshore direction, have been monitored on a weekly to bi-weekly basis since May, 2015 to date. Moreover, tides, waves, and winds have been measured for the same period (Figure 1b). Measured wave data presents several gaps owing to the instrument malfunction. Therefore, wave data corresponding to the NOAA Wave Watch III hindcast data (http://polar.ncep.noaa.gov/waves/hindcasts/) is validated with measured wave conditions at $10 \mathrm{~m}$ water depth and is further employed to correlate with measured beach changes.

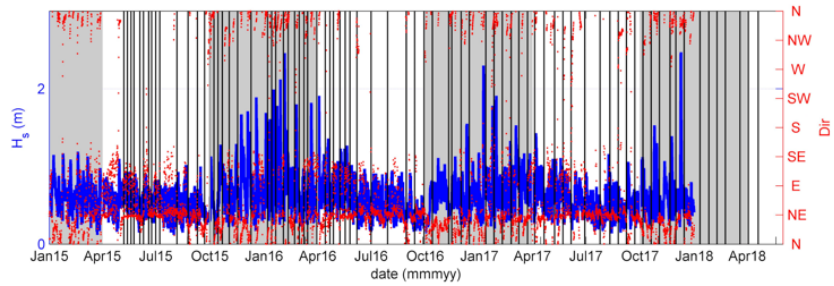

Figure 2 -Wave Watch III wave hindcast information $\left(\mathrm{H}_{\mathrm{s}}\right.$, Dir) at $10 \mathrm{~m}$ water depth and field surveying dates (vertical black lines). Gray/white background represent the storm/sea-breeze seasons.

Beach surveys were conducted by the same person using RTK-DGPS system. A total of 77 surveys to date (Figure 2) allow us to study the shoreline and beach volume evolution. Beach profile elevation is measured with respect to the geoid MEX97 (https://www.ngs.noaa.gov/GEOID/MEXICO97/). The survey data is employed to extract the shoreline position, the $+0.7 \mathrm{~m}$ contour line, and the sand volume of the subaerial and intertidal beach.

\section{RESULTS}

We employed an Empirical Orthogonal Function (EOF) analysis to identify the principal modes of beach variability and further correlate the changes with the wave (Figure 3a) and sea level (Figure 3b) conditions. Sea breeze events are more frequent and intense in April-May. On the other hand, Central American Cold Surges associated with cold-front passages occur in the fallwinter but are more intense in December-January where more energetic wave conditions are observed (Figure 3a). The mean sea level shows a seasonal variability with minimum and maximum monthly mean sea level occurring in July and October, respectively.
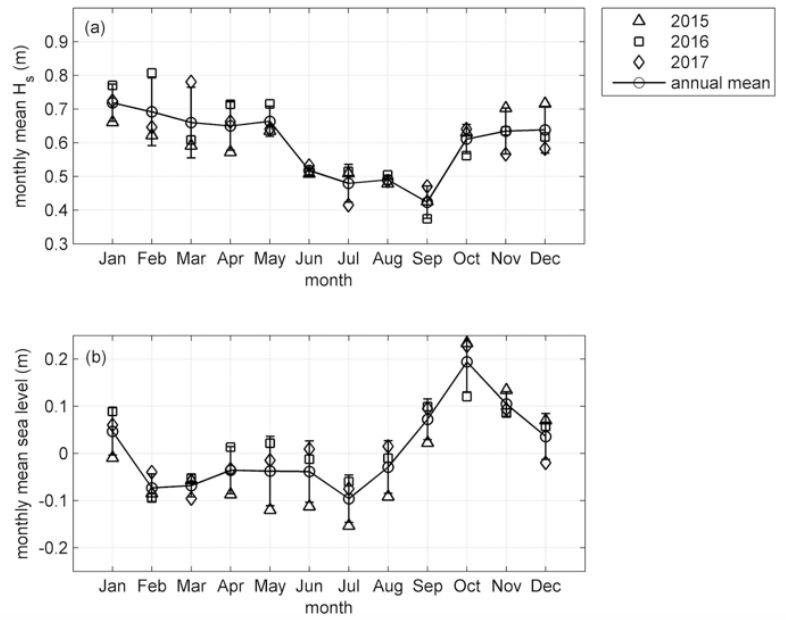

Figure 3 -Monthly mean (a) significant wave height and (b) sea level in the study area. 
The EOF analysis results for the first spatial and temporal mode are shown in Figure 4. Shoreline position presents a seasonal variability with an increasing trend that is strongly correlated with both the forcing conditions (sea breeze or cold-fronts) and the location with respect to the coastal structures (Jetty and Pier). Thus, near the jetty the beach width increases during the sea-breeze season, whereas the opposite behavior was observed west from the pier (Figures $4 \mathrm{a}$ and $4 \mathrm{~b}$ ). Also, an increasing trend on beach width is observed from February 2016 until the end of the measured period. This is consistent with the historical aerial pictures that suggested a beach width increase at rate of $5 \mathrm{~m} / \mathrm{year}$ approximately along the west half of the studied beach section (P11-P20). Intra-annual variability shows a clear difference in shoreline position variation during the winter of 2015-2016, as compared to the following two winter seasons (see Figure 4b), which might be associated to a low Southern Oscillation Index (SOI) or El Niño conditions.

The cross-shore location of the $+0.7 \mathrm{~m}$ contour line (Figures 4c and 4d) shows drastic changes in October of each year which correspond to the beginning of the cold-front season and the monthly maximum of the mean sea level (Zavala-Hidalgo et al, 2003). An advance of this subaerial contour line is observed during the whole period in a staircase mode. An exception occurred on May 2017 where there is an opposite change due to the occurrence of a strong local storm which lasted only one hour but induced a storm surge of $1.2 \mathrm{~m}$ and $H_{s}>2.5 \mathrm{~m}$. Finally, the subaerial volume evolution (Figure 4f) presented a sustained increase during the whole measured period (Figure 4f) owing to the sediment impoundment by the Port Jetty. The latter decreases with distance from the Jetty at P20 (Figure $4 \mathrm{e})$.
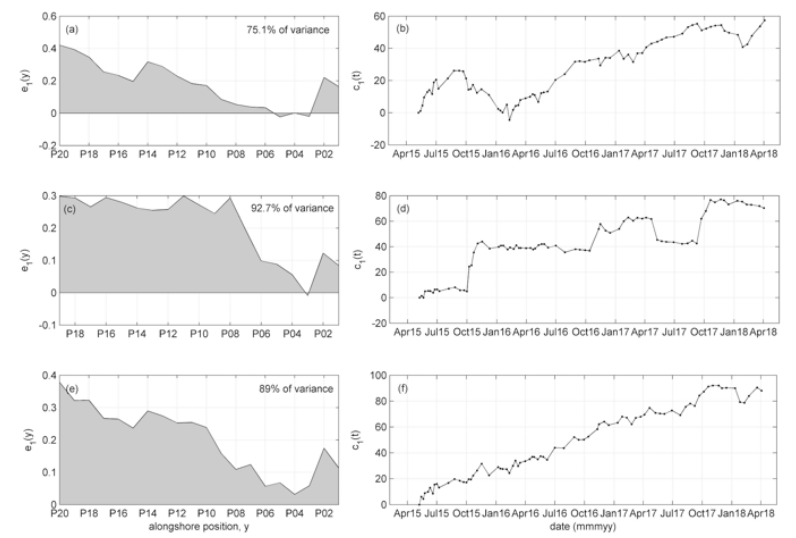

Figure 4 - First mode of spatial and temporal variability in Sisal beach for: $(a, b)$ shoreline position, $(c, d)+0.7 \mathrm{~m}$ contour line, and $(e, f)$ subaerial beach volume.

\section{CONCLUSIONS}

Beach surveys were conducted, on a sea breeze dominated beach, to investigate seasonal beach variability in the vicinity of coastal structures. Wave and mean sea level conditions present a seasonal variation that control such changes. The seasonal and intraannual morphodynamics are significantly affected by the presence of coastal structures. EOF analysis of the shoreline position and subaerial sand volume show a clear increasing trend of the beach during the whole period. Moreover, seasonal variations suggest beach rotation due to alongshore transport reversal during the sea-breeze and storm season. Such rotation in the shoreline position shows a clear difference between the winter of 2015-2016 and the following two winter seasons. The latter suggests that an increase in the intensity and occurrence of Central American Cold Surges, ascribed to a low SOI or El Niño conditions, induced a significant eastward sediment transport. The continuation of the monitoring program during the following years will allow a more thorough analysis of intra-annual variability.

\section{ACKNOWLEDGMENTS}

We thank to CONACYT (Programs Ciencia Básica 284819 and Cátedras 1146), DGAPA-UNAM

(IN101218), and Gobierno del Estado de Yucatán for financial support to conduct this study.

\section{REFERENCES}

Harley, Turner, Short, Ranasinghe (2010): Interannual variability and controls of the Sydeny wave climate, International Journal of Climatology, vol. 30, pp. 13221335.

Medellín, Mariño-Tapia, Euán-Ávila (2015): The influence of a Seawall on Postnourishment Evolution in a Sea-BreezeDominated Microtidal Beach, Journal of Coastal Research, vol. 31(6), pp. 1449-1458.

Reding (1992): The Central America Cold Surge: an observational analysis of the deep southward penetration of North American cold fronts, MSc. Thesis, Texas A\&M Univeristy, pp. 192.

Torres-Freyermuth, Puleo, DiCosmo, Allende-Arandía, Chardón-Maldonado, López, Figueroa-Espinoza, Ruiz de Alegría-Arzaburu, Figlus, Roberts Briggs, De la Roza, Candela (2017): Nearshore circulation on a sea breeze dominated beach during intense wind events, Continental Shelf Research, 151: 40-52.

Zavala-Hidalgo, Morey, O'Brien (2003): Seasonal circulation on the western shelf of the Gulf of Mexico using a high-resolution numerical model, Journal of Geophysical Research, 108, C12, 108(C12), 3389, doi:10.1029/2003JC001879. 